\title{
Transient thermal behavior of a microchannel heat sink with multiple impinging jets"
}

\author{
Ting-zhen $\mathrm{MING}^{\dagger 1,2,3}$, Yan DING ${ }^{3,4}$, Jin-le GUI ${ }^{3}$, Yong-xin $\mathrm{TAO}^{2}$ \\ $\left({ }^{1}\right.$ School of Civil Engineering and Architecture, Wuhan University of Technology, Wuhan 430070, China) \\ ( ${ }^{2}$ Department of Mechanical and Energy Engineering, University of North Texas, Denton 76207, USA) \\ $\left({ }^{3}\right.$ School of Energy and Power Engineering, Huazhong University of Science and Technology, Wuhan 430074, China) \\ $\left({ }^{4}\right.$ Department of Mechanical Engineering, University of Maryland, College Park 20742, USA) \\ 'E-mail: tzming@whut.edu.cn
}

Received Oct. 15, 2014; Revision accepted May 25, 2015; Crosschecked Oct. 12, 2015

\begin{abstract}
We performed a transient numerical investigation on a microchannel heat sink with multiple impinging jets (MHSMIJ) to explore the effects on the fluid flow and heat transfer characteristics of the MHSMIJ of an unsteady impinging jet and heat flux imposed upon the substrate surface by using a computational fluid dynamics method. The heat fluxes being imposed upon the substrate surface and the inlet velocities of the jet were all set as sinusoidal functions with different amplitudes and periods with time. The effects of the amplitudes and periods of the functions on the substrate properties were analyzed. Cooling performance was evaluated by calculating the periodic average surface heat transfer coefficient, average temperature uniformity, and temperature variation of the target surfaces over a period. The results indicated that the surface heat transfer coefficient and average temperature of the cooled surface oscillated with the periodic heat fluxes, accompanied by obvious phase lags. The phase lag has a significant dependence on the periods, but little dependence on the amplitudes. The material properties of the substrate have complex influences on the transient behavior of the MHSMIJ. The periodic heat flux and periodic jet velocity significantly affected the transient thermal performance of the MHSMIJ, but had less effect on its overall performance. Further, transient heat flux and jet velocity caused non-uniform and transient temperature distributions, which will cause thermal fatigue phenomenon, and thereby have effect on the longevity of the MHSMIJ.
\end{abstract}

Key words: Microchannel heat sink with impinging jets, Heat transfer, Sinusoidal heat flux, Sinusoidal inlet velocity, Phase lag doi: $10.1631 /$ jzus.A1400313

Document code: A

CLC number: TK121

\section{Introduction}

The development of high performance thermal systems has stimulated interest in methods to improve heat transfer rates, especially on the coolant side of hot surfaces. Most electronic components and systems with high heat flux generate heat which

\footnotetext{
* Project supported by the National Natural Science Foundation of China (No. 51106060), the Scientific Research Foundation of Wuhan University of Technology (No. 40120237), and the Research Project of Wuhan Metro Group Co., Ltd. (No. WHRT-KY-201016), China (iD) ORCID: Ting-zhen MING, http://orcid.org/0000-0002-9238-2637

(C) Zhejiang University and Springer-Verlag Berlin Heidelberg 2015
}

needs to be removed to ensure optimum operation, and thus thermal management of electronic devices becomes increasingly important. A number of innovative cooling techniques (Açıalın et al., 2005; Petroski et al., 2008; Huang and Yan, 2013; Huang et al., 2013; Lu et al., 2014) for low cost compact and reliable systems have been considered. The demand for more powerful cooling systems has, however, led to a search for unconventional methods.

Liquid jet impingement technique is a potential candidate for the enhancement of heat transfer in high heat flux cooling systems due to its proven ability to achieve high heat transfer coefficients with plain or enhanced surfaces (Wolf et al., 1993; 
Kandlikar and Bapat, 2007; Browne et al., 2010). Thus, the jet impingement technique is commonly employed for various cooling, heating, and drying applications in many industrial applications ranging from electronic component and gas turbine blade cooling, thermal drying of continuous sheets of materials and food-stuffs, manufacture of printed wiring boards and metal sheets, printing processes, de-icing of aircraft wings, as well as the tempering of glass and nonferrous metal sheets, etc. (Lienhard, 1995). Generally, the superior heat transfer performance of liquid jet impingement is attributed to the fact that the impinging jet decreases the thickness of the liquid film on the heated surface, and thus reduces the thermal resistance between the heated surface and the impinging flow.

Many investigations have been made in related areas in recent years. Specifically, an experimental investigation was performed to study the effect of the profile of a convergent nozzle on the local heat transfer performance of a smooth flat surface (Limaye et al., 2013). The results indicated that the distribution of the $N u$ number and the recovery factor are significantly affected by the profile of the convergent nozzle, particularly at lower nozzle-to-plate distances in the stagnation point region but not in the wall jet region. The cooling behavior of the jet impingement of a droplet train, and free surface jets over a heated and pre-wetted surface was explored employing an algebraic volume-of-fluid methodology (Lewis et al., 2013). Some numerical analysis was carried out. The heat transfer from an isothermally heated flat surface due to $2 \mathrm{D}$ turbulent twin oblique confined slot-jet impingement was studied numerically using the ANSYS FLUENT commercial code. The local $N u$ number distribution predicted by the SST $k$ - $\omega$ model agrees well with the existing experimental data. Further, the average $N u$ number is a strong direct function of the Re number and the jet impingement angle, whereas it is a weak inverse function of the separation distance between the jet and the target plate (Afroz and Sharif, 2013). Jet impingement heat transfer from a round gas jet to a flat wall was numerically investigated (Jensen and Walther, 2013). Later, Poncet et al. (2013) performed a new calculation using an innovative Reynolds stress model (RSM); they compared the calculated velocities to the measurements performed by the particle image velocimetry (PIV) technique.

To improve temperature uniformity and to achieve a higher heat transfer performance, various concepts of combining jet impingement cooling with other heat transfer technologies have been proposed. The combination of impinging jet and microchannel cooling, which is destined to become a potential thermal management tool in the future, has attracted increasing attention, and related research studies have been performed (Chang and Dhir, 1995; Jang et al., 2003; Lelea et al., 2004; Gül, 2006; Barrau et al., 2010; Lelea, 2010; 2012; Shalchi-Tabrizi and Seyf, 2012). Specifically, a new hybrid cooling scheme has been proposed for high heat flux management and power devices. The hybrid cooling scheme has been shown to have the capacity to optimize the temperature uniformity of the cooled object (Barrau et al., 2010). The turbulent flow field in a tube heated uniformly from the wall was experimentally studied with fluid being injected tangentially (Chang and Dhir, 1995). Some researchers (Jang et al., 2003) experimentally investigated a microchannel heat sink subjected to an air impinging jet. They demonstrated that, under certain conditions, up to $48.5 \%$ cooling efficiency improvement was achieved compared with that achieved with traditional microchannel design, with the maximum pressure loss reduced by $90.5 \%$. The geometry of the tangential heat sink with straight circular microchannels was optimized (Lelea, 2010).

From the literature review shown above, it is obvious that both microchannel heat sink and impinging jet have attracted wide attention for their excellent advantages in heat transfer performance. Various experimental results and steady state numerical simulations on microchannel heat sink with an impinging jet (MHSIJ) have also been published. However, to the best of our knowledge, there is little analytical and numerical work which has studied the effects of periodic heat flux and periodic jet velocity on the thermal performance of an MHSIJ. Existing research mainly has focused on the physical mechanism of the impinging jet without considering its application in microchannel heat sinks (Camci and Herr, 2002; Hofmann et al., 2007; Saeid, 2009; Xu et al., 2010; 2012). Saeid (2009) presented a meaningful 
pioneer exploration on the fluid flow and heat transfer performance of a channel with oscillating jet velocity, indicating that transient thermal behavior has aroused researchers' attention. However, this research mainly considered a $2 \mathrm{D}$ model with a single impinging jet, which is to some extent different from a 3D microchannel heat sink with multiple impinging jets (MHSMIJ). As we know, the working conditions of transient jet velocity and heat flux are sometimes confronted in industrial applications. Periodic working conditions of velocity and heat flux will not only affect the fluid flow and heat transfer performance of MHSMIJs, but also cause severe thermal fatigue phenomenon (Ming and Zhao, 2012) which will decrease the longevity of electronic devices with high heat fluxes. However, before solving the problems caused by the thermal fatigue phenomenon, the qualitative and quantitative analysis of the transient thermal behavior of MHSMIJs suffering from periodic jet velocity and heat flux is very important. In this study, we performed a numerical analysis on an MHMSIJ being imposed by periodic jet velocities and heat fluxes, analyzed the transient fluid flow and thermal behavior, explored the effects of amplitude and period of jet velocity and heat flux, and also considered the effect of the physical properties of the substrate materials.

\section{Mathematical model and numerical method}

\subsection{Physical model}

As can be seen in Fig. 1a, a very high periodic heat flux is imposed upon the heated surface of the substrate, and energy transfers through the substrate to the cooled surface. Water coolant flows through the top jet inlets impinging the cooled surface, causing strong heat transfer and cooling the whole substrate. The actual geometrical model is shown in Fig. 1b; there are 12 uniform distribution jet inlets of the same size, located on the top surface of the MHSMIJ. The coolant first moves through each jet inlet, then flows past the channel and exits from an outlet on each side. Assuming symmetric properties to be perpendicular to both the length and width, only a quarter of the entire system needs to be taken into account. The entire geometric dimensions of this
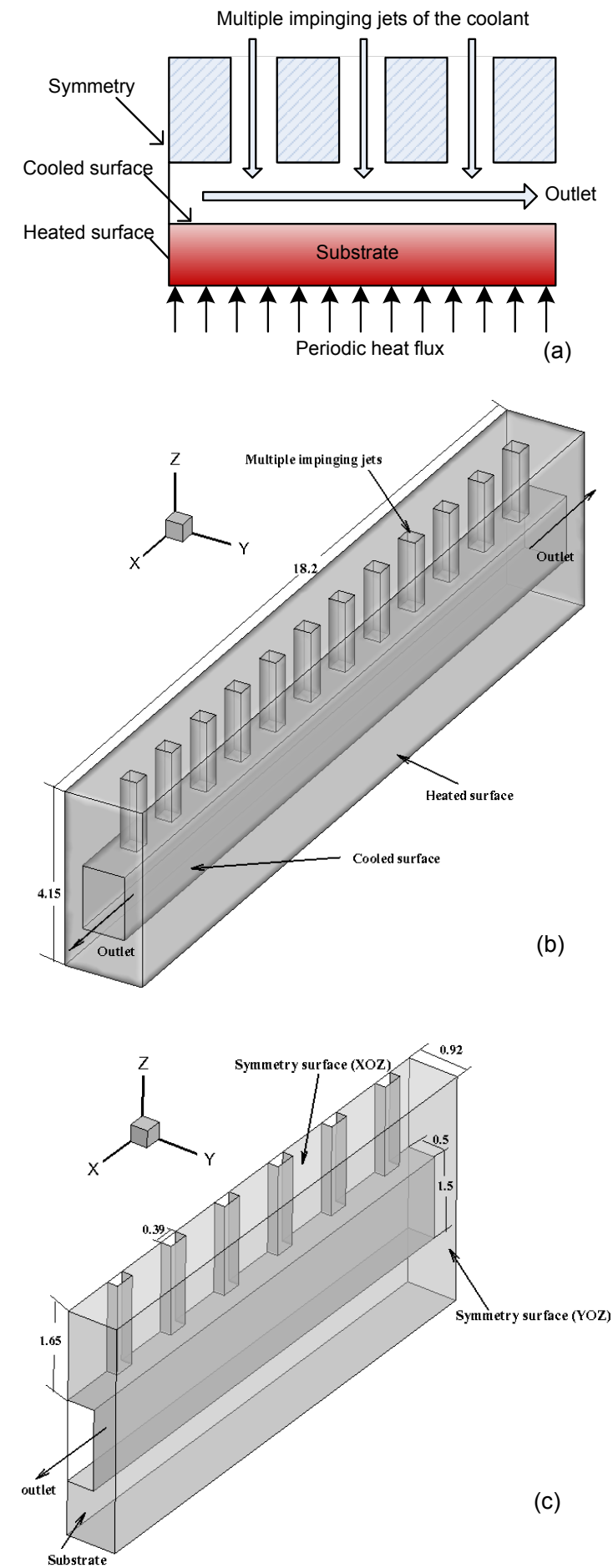

Fig. 1 Schematic of the MHSMIJ: (a) physical model of MHSMIJ; (b) the entire heat sink channel; (c) computational model (unit: $\mathbf{m m}$ )

heat sink are 9.1, 0.92, and $4.15 \mathrm{~mm}$ in length, width, and height directions, respectively. For one thing, the length, width, and height of the MHSMIJ are 9.1, 0.5, 
and $1.5 \mathrm{~mm}$, respectively; for another, the square cross-section of the jet inlet is adopted with the side length being $0.39 \mathrm{~mm}$. In addition, the material of the MHSMIJ and the coolant are copper and water, respectively, with the inlet temperature of the coolant being $280 \mathrm{~K}$.

\subsection{Mathematical model}

The present model is based on the following assumptions: (1) the working fluid (water) in the channel is considered as incompressible, as the density variation is comparatively small during the temperature variation scope, but its thermal conductivity and dynamic viscosity are temperature-dependent; (2) since the characteristic length of the channel in our case is in the range of $1 \mu \mathrm{m}-1 \mathrm{~mm}$ (Guo and $\mathrm{Li}$, 2003), it meets the flow continuum hypothesis. Thus, the mass equation, Navier-Stokes equations, and energy equation are all applicable in this condition:

Mass equation:

$$
\frac{\partial \rho}{\partial t}+\frac{\partial(\rho u)}{\partial x}+\frac{\partial(\rho v)}{\partial y}+\frac{\partial(\rho w)}{\partial z}=0 .
$$

Navier-Stokes equations:

$$
\begin{gathered}
\frac{\partial u}{\partial t}+\frac{\partial(u u)}{\partial x}+\frac{\partial(u v)}{\partial y}+\frac{\partial(u w)}{\partial z}=\frac{\partial}{\partial x}\left(v \frac{\partial u}{\partial x}-u^{2}\right) \\
+\frac{\partial}{\partial y}\left(v \frac{\partial u}{\partial y}-u v\right)+\frac{\partial}{\partial z}\left(v \frac{\partial u}{\partial z}-u w\right)-\frac{1}{\rho} \frac{\partial p}{\partial x}, \\
\frac{\partial v}{\partial t}+\frac{\partial(v u)}{\partial x}+\frac{\partial(v v)}{\partial y}+\frac{\partial(v w)}{\partial z}=\frac{\partial}{\partial x}\left(v \frac{\partial v}{\partial x}-u v\right) \\
+\frac{\partial}{\partial y}\left(v \frac{\partial v}{\partial y}-v^{2}\right)+\frac{\partial}{\partial z}\left(v \frac{\partial v}{\partial z}-v w\right)-\frac{1}{\rho} \frac{\partial p}{\partial y}, \\
\frac{\partial w}{\partial t}+\frac{\partial(w u)}{\partial x}+\frac{\partial(w v)}{\partial y}+\frac{\partial(w w)}{\partial z}=\frac{\partial}{\partial x}\left(v \frac{\partial w}{\partial x}-u v\right) \\
+\frac{\partial}{\partial y}\left(v \frac{\partial w}{\partial y}-v^{2}\right)+\frac{\partial}{\partial z}\left(v \frac{\partial w}{\partial z}-v w\right)-\frac{1}{\rho} \frac{\partial p}{\partial z} .
\end{gathered}
$$

Energy equation:

$$
\begin{aligned}
& \frac{\partial T}{\partial t}+\frac{\partial(u T)}{\partial x}+\frac{\partial(v T)}{\partial y}+\frac{\partial(w T)}{\partial z} \\
& =\frac{1}{\rho C_{\mathrm{P}}}\left(\frac{\partial}{\partial x}\left(k \frac{\partial T}{\partial x}\right)+\frac{\partial}{\partial y}\left(k \frac{\partial T}{\partial y}\right)+\frac{\partial}{\partial z}\left(k \frac{\partial T}{\partial z}\right)\right)+S_{T},
\end{aligned}
$$

where $\rho$ and $p$ are the fluid density and pressure, respectively; $u, v$, and $w$ are the velocity components in the $x, y$, and $z$ directions; $x, y$, and $z$ are the directions of width, depth, and length of the MHSMIJ, respectively, shown in Fig. $1 ; v, k$, and $C_{\mathrm{P}}$ are the kinematic viscosity, heat conductivity coefficient, and specific heat at constant pressure, respectively; and $T$ represents the temperature. Since the inlet boundary condition changes with time, we need to take the unsteady item into account. In addition, for Eq. (5), the first term in the left hand side represents the unsteady term, the rest of them on the left represent the fluid convection terms. On the right hand side, the first three terms are thermal diffusion terms, and $S_{T}$ is the viscous dissipation term.

The fluid physical properties will influence the heat transfer process. Here, the thermal conductivity and dynamic viscosity $(\mu)$ are temperature-dependent, which can be described as follows (Li, 2010):

$$
\begin{gathered}
k=-10^{-5} T^{2}+0.0094 T-1.0887, \\
\mu=\rho \nu=2 \times 10^{11} T^{-5.7905} .
\end{gathered}
$$

Re number at the inlet is defined as

$$
R e=\frac{\rho V d}{\mu},
$$

where $V$ and $d$ are respectively the fluid inlet velocity and the channel hydraulic diameter which is defined as four times the inlet jet cross sectional area over its wetted perimeter.

\subsection{Boundary conditions}

\section{Inlet boundary}

As shown in Fig. 1b, we impose constant or transient velocities on the inlets in different cases. The velocity is perpendicular to the inlet surface and uniform; the temperature $T_{\text {in }}$ is also uniform and is set constant at $280 \mathrm{~K}$.

$$
\begin{gathered}
w=\bar{v}+A_{v} \times \sin \left(\frac{2 \pi}{\tau_{v}} t\right), \\
u=w=0, \\
T=T_{\text {in }},
\end{gathered}
$$

where $A_{v}$ and $\tau_{v}$ are the amplitude and period of 
velocity variation, respectively, which vary with different cases.

\section{Wall surface}

According to different cases, a sinusoidal heat flux $q$ shown in Eq. (12) is imposed upon the bottom surface, which is nominated as the heated surface in Fig. 1 .

$$
q=\bar{q}+A_{\mathrm{h}} \times \sin \left(\frac{2 \pi}{\tau_{\mathrm{h}}} t\right)
$$

The values of the amplitude $\left(A_{\mathrm{h}}\right)$ and period $\left(\tau_{\mathrm{h}}\right)$ of heat flux vary with different cases. The lateral surfaces are set as adiabatic as no other heat is considered entering the MHSMIJ. In addition, the contact surfaces of the solid with the fluid inside the channel are regarded as coupled surfaces, upon which we need not impose any condition; the temperature distribution can be calculated according to conjugate heat transfer between the solid and the fluid.

To facilitate the process of analyzing the effect of each boundary condition (inlet velocity and heat flux of the wall surface), we can let one be constant and the other vary with time. For instance: if the inlet velocity varies with time, the heat flux on the heated surface will be kept constant.

\section{Outlet boundary}

In all the cases in this study, the outlet is treated as a pressure outlet boundary condition. That is, the gauge pressure of the outlet is 0 :

$$
P_{\mathrm{r}, \text { out }}=0 \text {. }
$$

\section{Symmetry surfaces}

As mentioned above, as the model in this case is symmetric both in length and in width, the symmetry boundary condition is set to alleviate the computing process. Thereby, only a quarter of the geometrical model (Fig. 1c) can be selected for the numerical analysis without considering the whole model as shown in Fig. 1b, which will save the computer resources.

\subsection{Meshing skills}

In general, for the same meshing zone, the hexahedral (HEX) meshing method is more economical and can reduce false diffusion more efficiently than the tetrahedral method. As a result, HEX grids were applied in the model and the mesh generation procedure of the whole geometric model was executed using the commercial software package Gambit 2.3.16. Fig. 2 shows the grid distribution of the computational model. Because of the thin boundary layer formed at the impinging region, the grids need to be more concentrated than in the other zones. In the regions of possible high temperature gradient, finer grids were adopted for an accurate description of the thermal boundary layer. The same consideration was also taken into effect for the velocity gradient and the velocity boundary layer.

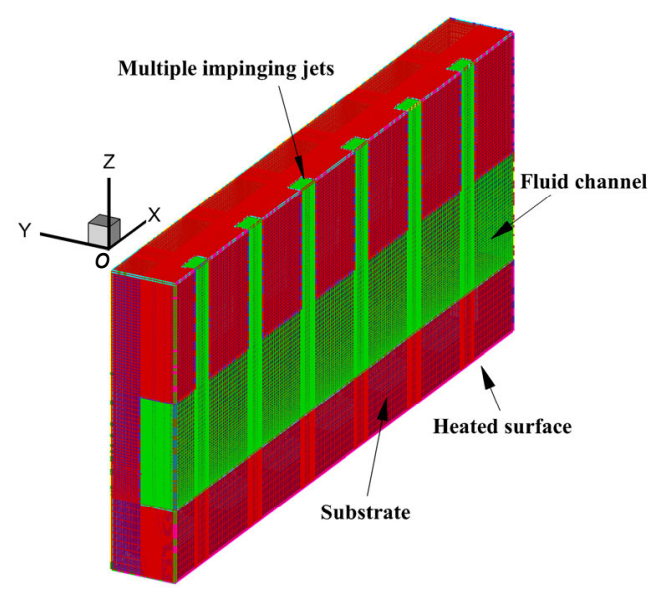

Fig. 2 Grid system of the computational model

\subsection{Computational procedure}

The numerical simulations were performed by using the general purpose CFD program Fluent 6.3.26. The QUICK scheme (Hayase et al., 1992) was used to discretize the convective terms, and a second-order accurate treatment was used for the diffusion terms. The set of discretized algebraic equations was solved in a coupled manner. Before conducting the numerical simulation process, we calculated that the Re number in the channel was about 2500 with the minimum velocity of the jet inlet being $2.74 \mathrm{~m} / \mathrm{s}$. Extensive research reports indicated that the classical transition values from laminar to turbulent flow regime are 1000-2500 (Li et al., 2003; Rands et al., 2006; Tang et al., 2007; Morini and Lorenzini, 2009). All these results were found with clear microtubes being the test sections. However, in this study, the model was so complex that the 
12 impinging jets join and mix in the main flow of the channel causing strong turbulence. So the RNG $k-\varepsilon$ model was adopted to more effectively describe the higher strain curvature and larger bending degree of the streamline. The central differencing scheme was used for the diffusion terms. The discretized equations were solved following the SIMPLEC algorithm. Relaxation factors were used to avoid divergence in the iteration. The typical relaxation factors were used as 0.7 for momentum equations, 0.3 for the pressure, and 0.9 for the energy equation. The minimum period of all the cases was $5 \mathrm{~s}$. When the time step was $0.1 \mathrm{~s}$, the simulation results were accurate enough to describe the transient characteristics of the MHSMIJ. The iterations were continued until the relative error in the mass conservation equation was below $1 \times 10^{-5}$ and that in the energy equation below $1 \times 10^{-8}$.

To test the grid-independent performance of the grid system selected in the numerical simulation, three test cases of the computational model under steady state conditions (heat flux was $400 \mathrm{~W} / \mathrm{cm}^{2}$, jet velocity was $2.74 \mathrm{~m} / \mathrm{s}$ ) with grid numbers being 856128,1237500 , and 1694088 were tested. Numerical simulation results indicated that the average temperatures of the cooled surface are $307.14 \mathrm{~K}$, $310.25 \mathrm{~K}$, and $312.02 \mathrm{~K}$ corresponding to the three mesh systems listed above. It can be seen that when we add almost the same amount of grid numbers, about 400000 , the differences of average temperature are $3.11 \mathrm{~K}$ and $1.77 \mathrm{~K}$, separately, which means the difference becomes less obvious with increasing grid numbers. Such a small discrepancy is acceptable especially when considering the numerical simulation cost resulting from an increase of grid numbers. In addition, by comparing the three mesh systems, we found that there was only a deviation of approximately $1 \%$ between these two results, which also demonstrated that the solution in this case was gridindependent. The number of 1237500 was thus selected as the basic mesh system in this study.

\section{Results and discussion}

\subsection{Heat transfer performances}

To better understand the effect of transient periodic processes on the thermal performance of the system, many periods have been simulated continuously to avoid the effect of initial conditions. For example, in any point of the MHSMIJ, when the temperature curve of the $N$ th period is almost the same as that of the $(N+1)$ th period, we get the result without the effect of the initial condition of the numerical simulation. Then, the results of the $N$ th period can be shown and be analyzed. Here, we define this period as $N_{\mathrm{s}}$. However, in the following parts, the period number is much larger than $N_{\mathrm{s}}$. During calculation, each period is divided into 5 time steps.

Figs. 3 and 4 show the surface heat transfer coefficient and the isotherms at the cooled surface, respectively, in the 32 nd period with $q=500+$

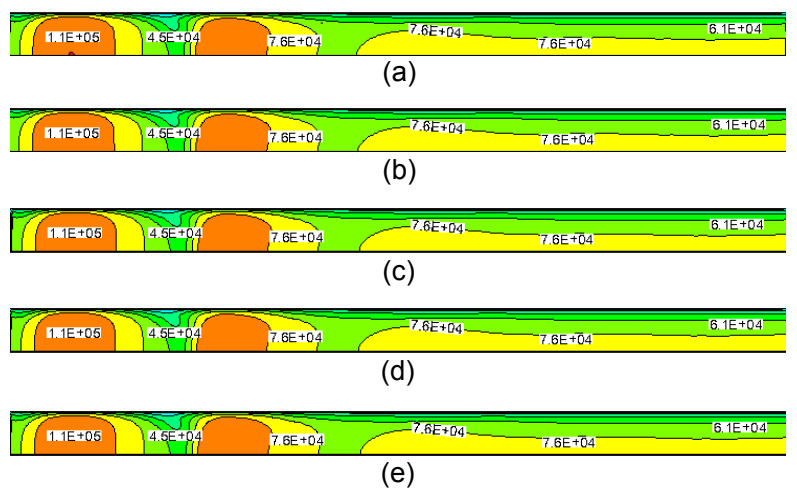

Fig. 3 Surface heat transfer coefficient at the cooled surface with $q=500+300 \times \sin \left(\frac{2 \pi}{10} t\right) \quad \mathrm{W} / \mathrm{cm}^{2}$ and $V=$ $2.74 \mathrm{~m} / \mathrm{s}$

(a) $t=\tau_{\mathrm{h}} / 5$; (b) $t=2 \tau_{\mathrm{h}} / 5$; (c) $t=3 \tau_{\mathrm{h}} / 5$; (d) $t=4 \tau_{\mathrm{h}} / 5$; (e) $t=5 \tau_{\mathrm{h}} / 5$

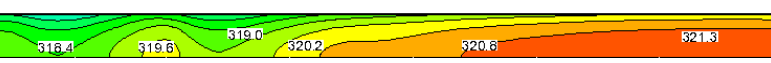

(a)

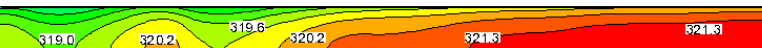

(b)

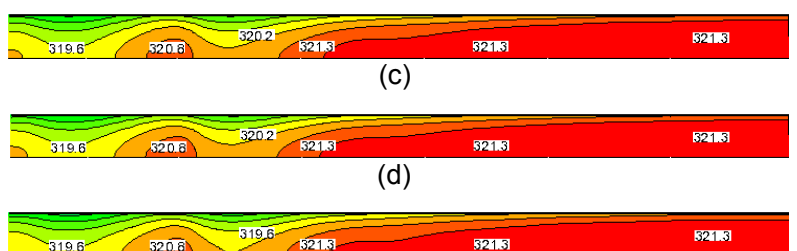

(e)

Fig. 4 Isotherms at the cooled surface with $q=500+300 \times \sin \left(\frac{2 \pi}{10} t\right) W / \mathrm{cm}^{2}$ and $V=2.74 \mathrm{~m} / \mathrm{s}$ (unit: $\mathrm{K}$ )

(a) $t=\tau_{\mathrm{h}} / 5$; (b) $t=2 \tau_{\mathrm{h}} / 5$; (c) $t=3 \tau_{\mathrm{h}} / 5$; (d) $t=4 \tau_{\mathrm{h}} / 5$; (e) $t=5 \tau_{\mathrm{h}} / 5$ 
$300 \times \sin \left(\frac{2 \pi}{10} t\right) \mathrm{W} / \mathrm{cm}^{2}$ and $V=2.74 \mathrm{~m} / \mathrm{s}$. Since the model in this case is symmetric both in length and width, a quarter of the geometrical model is used for simulation here. So the figures represent just a quarter of the cooled surface. In this case, $N_{\mathrm{s}}=28$, so the results of the 32nd period are immune to the effect of the initial conditions. The left side of these figures is the upstream and the right side the downstream. Fig. 3 shows the surface heat transfer coefficient at the cooled surface. The surface heat transfer coefficient of the upstream area impinged by the jet is larger than that of other areas. The reason is that the impinging jet decreases the thickness of the liquid film on the heater surface, and thus reduces the thermal resistance between the heated surface and the impinging flow. In addition, intensive flow mixing also plays a role. Understandably, liquid jet impinging heat transfer is most efficient at the impinging region (stagnation) and becomes lower with increasing distance from the stagnation zone. However, because the upstream jets collect in the channel to be a mainstream flow, water from the downstream jets cannot directly impinge onto the cooled surface. Therefore, the impinging flow combined with the fluid stream comes out from the microchannel outlet. As shown in Figs. 3 and 4, the left side has comparatively higher heat transfer coefficient and lower surface temperature. This is easy to understand since a higher heat transfer coefficient means a better cooling effect.

Figs. 5 and 6 show the heat transfer coefficient $h$ and isotherms at the cooled surface in the 39th period with $q=500 \mathrm{~W} / \mathrm{cm}^{2}$ and $V=10.96+7 \times$ $\sin \left(\frac{2 \pi}{1} t\right) \mathrm{m} / \mathrm{s}$. In this case, $N_{\mathrm{s}}=26$. We can also see that the values of $h$ and $T$ oscillate with time. The heat transfer coefficients at $t=3 \tau_{\mathrm{h}} / 5$ and $t=4 \tau_{\mathrm{h}} / 5$ in Fig. 5 are higher than those at other times. Since a higher $h$ indicates better cooling performance, the temperatures of the cooled surface at $t=3 \tau_{\mathrm{h}} / 5$ and $t=4 \tau_{\mathrm{h}} / 5$ are lower than the others. The transient jet inlet velocity can increase the flow mixing rate, which in turn reduces the boundary layer thickness of the target surface. Similarly, the heat transfer coefficient of the upstream area is larger than that of the downstream areas. This phenomenon has been shown in Figs. 3 and 4 and explained above.

\begin{tabular}{|c|c|c|c|c|c|}
\hline$\sqrt{12 E+05}$ & $\sqrt{6.9 E+04}$ & 1.11E+ 05 & $9.6 E+04$ & $-9.6 E+04-$ & $9.6 E+04$ \\
\hline \multicolumn{6}{|c|}{ (a) } \\
\hline $1.2= \pm 0.5$ & $11.1 \mathrm{E}+05^{5}$ & (1.212 $= \pm 05$ & (1.1E+05 & $-1.1 E+05$ & $1.1 \mathrm{E}+05$ \\
\hline \multicolumn{6}{|c|}{ (b) } \\
\hline [1.21 $= \pm 0.55$ & 1.:2 $=+0.55$ & [1:2 $2= \pm 0.05$ & TारिE+051 & $1.21=+05$ & $-122 E+0.55$ \\
\hline \multicolumn{6}{|c|}{ (c) } \\
\hline$[1,2= \pm 0.5$ & 1.21: $=+0.5$ & 1.12: $= \pm 0.5$ & $\sqrt{1 / 2 E+05}$ & $1.2 E+05$ & $-1.2 E+05$ \\
\hline \multicolumn{6}{|c|}{ (d) } \\
\hline $1,2=+005$ & $\int_{9.6 \mathrm{E}+04}$ & $11.1 E+05$ & $\overline{\overline{1.1 E+05}}$ & $1.1 E+05$ & $6 E+04$ \\
\hline
\end{tabular}

(e)

Fig. 5 Surface heat transfer coefficient at the cooled surface with $q=500 \mathrm{~W} / \mathrm{cm}^{2}, V=10.96+7 \times \sin \left(\frac{2 \pi}{1} t\right) \mathrm{m} / \mathrm{s}$ (a) $t=\tau_{\mathrm{h}} / 5$; (b) $t=2 \tau_{\mathrm{h}} / 5$; (c) $t=3 \tau_{\mathrm{h}} / 5$; (d) $t=4 \tau_{\mathrm{h}} / 5$; (e) $t=5 \tau_{\mathrm{h}} / 5$

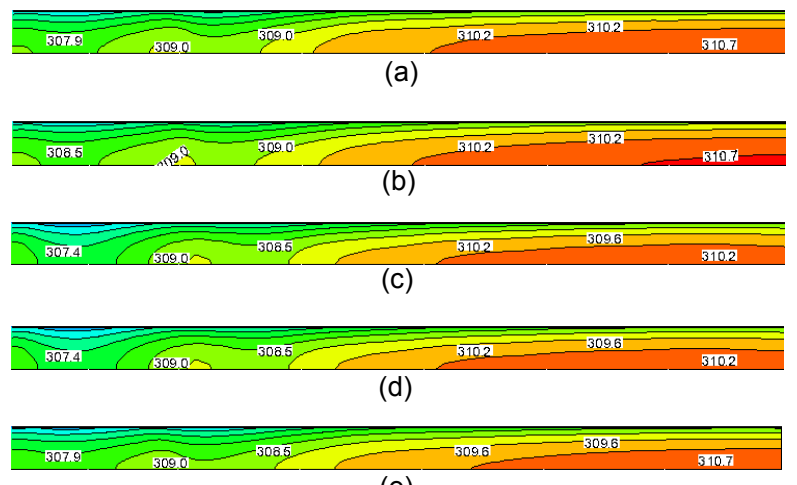

(e)

Fig. 6 Isotherms at the cooled surface with $q=500 \mathrm{~W} / \mathrm{cm}^{2}$, $V=10.96+7 \times \sin \left(\frac{2 \pi}{1} t\right) \mathrm{m} / \mathrm{s}$

(a) $t=\tau_{\mathrm{h}} / 5$; (b) $t=2 \tau_{\mathrm{h}} / 5$; (c) $t=3 \tau_{\mathrm{h}} / 5$; (d) $t=4 \tau_{\mathrm{h}} / 5$; (e) $t=5 \tau_{\mathrm{h}} / 5$

\subsection{Effect of periodic heat flux}

In this part, we mainly focus on the effect of periodic heat flux on the heat transfer performance of the MHSMIJ. As we know, the temperature of the cooled surface decreases with increasing heat transfer coefficient, which means the cooling performance of the MHSMIJ is improved. Therefore, it is reasonable to use the average temperature of the surface or the heat transfer coefficient to analyze the thermal performance of the system. 
According to Eqs. (9) and (12), the heat transfer process is transient. To evaluate the thermal performance of the system, it is meaningful to introduce an average temperature $\left(T_{\mathrm{S}, \mathrm{P}}\right)$ defined as the periodic average value of the area-average temperature of the cooled surface, and $T_{\mathrm{S}, \mathrm{P}}$ can be written as

$$
T_{\mathrm{S}, \mathrm{P}}=\frac{1}{\tau} \int_{t_{0}}^{t_{0}+\tau} T_{\mathrm{S}} \mathrm{d} t
$$

where $T_{\mathrm{S}}$ and $t_{0}$ are the area-average temperature of the cooled surface at a given time and the initial time of a considered period, respectively; $\tau$ is the period of the jet velocity or the heat flux. Thereby, the value of $T_{\mathrm{S}, \mathrm{P}}$ is an average value based on the surface and the time period.

We define $\Delta T_{\mathrm{m}, \mathrm{P}}$ as the difference of the maximum and minimum temperatures on the cooled surface at any given period:

$$
\Delta T_{\mathrm{m}, \mathrm{P}}=T_{\max , \mathrm{P}}-T_{\min , \mathrm{P}} .
$$

In addition, $h_{\mathrm{S}, \mathrm{P}}$ is defined as the area-averaged heat transfer coefficient during a period, which is shown as

$$
h_{\mathrm{S}, \mathrm{P}}=\frac{1}{\tau} \int_{t_{0}}^{t_{0}+\tau} h_{\mathrm{S}} \mathrm{d} t,
$$

where $h_{\mathrm{S}}$ is the area-weighted average surface heat transfer coefficient. Then, we define $\Delta h_{\mathrm{m}, \mathrm{P}}$ as the difference of the maximum and minimum heat transfer coefficients on the cooled surface at any given period:

$$
\Delta h_{\mathrm{m}, \mathrm{P}}=h_{\max , \mathrm{P}}-h_{\min , \mathrm{P}}
$$

Fig. 7 shows the effect of period on $T_{\mathrm{S}, \mathrm{P}}$ and $\Delta T_{\mathrm{m}, \mathrm{P}}$ with a sinusoidal heat flux being imposed upon the heated surface. Herein, $q=500+300 \times$ $\sin \left(\frac{2 \pi}{10} t\right) \mathrm{W} / \mathrm{cm}^{2}$ and the jet inlet velocity is fixed at $2.74 \mathrm{~m} / \mathrm{s}$, and $N_{\mathrm{s}}=28 . T_{\mathrm{S}, \mathrm{P}, \mathrm{C}}$ and $T_{\mathrm{S}, \mathrm{P}, \mathrm{H}}$ represent the values of $T_{\mathrm{S}, \mathrm{P}}$ upon the cooled surface and the heated surface, respectively; $\Delta T_{\mathrm{m}, \mathrm{P}, \mathrm{C}}$ and $\Delta T_{\mathrm{m}, \mathrm{P}, \mathrm{H}}$ represent the values of $\Delta T_{\mathrm{m}, \mathrm{P}}$ upon the cooled surface and heated surface, respectively.

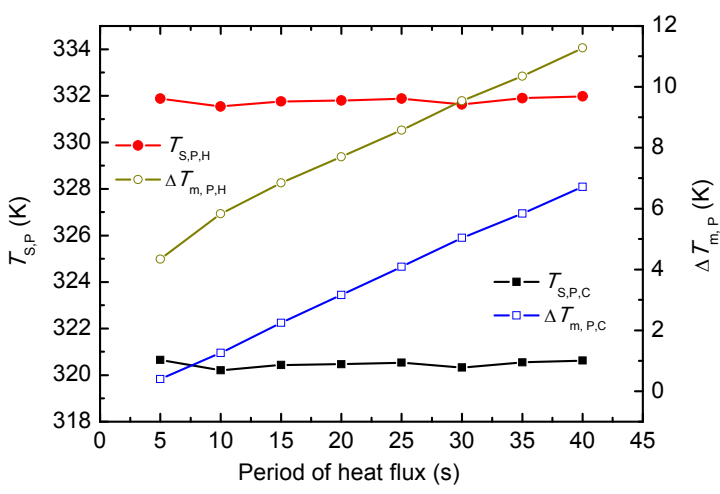

Fig. 7 Values of $T_{\mathrm{S}, \mathrm{P}}$ and maximum temperature variation at the cooled surface and the heated surface with the variation of period of the heat flux

From Fig. 7, the values of $T_{\mathrm{S}, \mathrm{P}, \mathrm{H}}$ and $T_{\mathrm{S}, \mathrm{P}, \mathrm{C}}$ vary less than $1 \mathrm{~K}$ with increasing period. For all cases, the values of $T_{\mathrm{S}, \mathrm{P}, \mathrm{H}}$ and $T_{\mathrm{S}, \mathrm{P}, \mathrm{C}}$ are around $331.8 \mathrm{~K}$ and $320.5 \mathrm{~K}$, respectively. This means that the overall cooling performance of the MHSMIJ is independent of the period of the heat flux on the heated surface. However, as the period increases, both $\Delta T_{\mathrm{m}, \mathrm{P}, \mathrm{H}}$ and $\Delta T_{\mathrm{m}, \mathrm{P}, \mathrm{C}}$ increase more significantly, which means the temperature uniformity is deteriorated by higher period $\tau$. When the period is $40 \mathrm{~s}, \Delta T_{\mathrm{m}, \mathrm{P}, \mathrm{H}}$ and $\Delta T_{\mathrm{m}, \mathrm{P}, \mathrm{C}}$ are about $11.5 \mathrm{~K}$ and $7 \mathrm{~K}$, respectively. However, these two values are about $4.5 \mathrm{~K}$ and $0.5 \mathrm{~K}$, respectively, when the period is $5 \mathrm{~s}$.

Fig. 8 shows the effect of period on $h_{\mathrm{S}, \mathrm{P}}$ and $\Delta h_{\mathrm{m}, \mathrm{P}}$ with a sinusoidal heat flux being imposed upon the heated surface. From this figure, the values of $h_{\mathrm{S}, \mathrm{P}}$ vary slightly, and there is only a deviation of approximately $0.2 \%$ between different periods, which is consistent with the results of Fig. 7 since the temperature of the cooled surface decreases with increasing heat transfer coefficient. This also shows that the overall cooling performance of the heat sink has little dependence on the period of the heat flux upon the heated surface. However, as the period increases, $\Delta h_{\mathrm{m}, \mathrm{P}}$ increases more significantly.

As we know, a non-uniform temperature distribution on the surface will be harmful to the performance of the heat sink. Firstly, a best temperature gradient should be perpendicular to the wall surface, and heat will be effectively transferred to the fluid. However, under the same heat flux boundary condition, a larger temperature gradient of the surface will cause the heat to be transferred within the substrate 
without being directly transferred to the fluid. Secondly, a non-uniform temperature distribution of the surface will cause non-uniform temperature distributions all through the substrate material, which will cause thermal stress. This thermal stress will not affect the system performance over a short time period, but it will have a serious influence on the overall performance of the system in the long run, as the thermal fatigue phenomenon occurs frequently due to frequent variation of temperature and frequent expansion/compression of material. Thereby, from the point of view of heat transfer, $T_{\mathrm{S}, \mathrm{P}}$ is a very important parameter for assessing the enhancement of heat transfer by using a transient boundary condition. However, if we pay more attention to the life span and the reliability of MHSMIJs, $\Delta T_{\mathrm{m}, \mathrm{P}}$ is another more important parameter for assessing its reliability under transient boundary conditions, and can be an index to analyze what is the range of boundary conditions in which the MHSMIJ can be operated safely without undue reduction of its life span. In this way, from Fig. 7, we can see that a shorter period is favorable to the overall performance of an MHSMIJ.

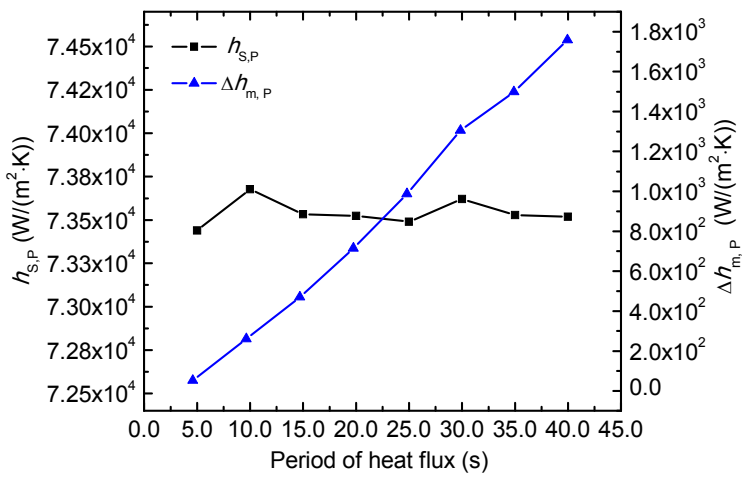

Fig. 8 Variation of $h_{\mathrm{S}, \mathrm{P}}$ and $\Delta \boldsymbol{h}_{\mathrm{m}, \mathrm{P}}$ at the cooled surface with the variation of period of the heat flux

When a heat flux is imposed upon the heated surface, it will be transferred through the substrate to the cooled surface and finally to the liquid fluid. It is known that the heat flux in any cross-section perpendicular to its direction will experience a fluctuation if the original heat flux imposed on the heated surface varies with time. The fluctuation will attenuate and has a time lag at different cross-sections and at different periods. The time lag $t_{\text {lag }}$ between the cooled surface and the heated surface is an interesting pa- rameter for assessing the thermal performance of MHSMIJs. To further understand the hysteresis phenomenon, a new nomenclature phase lag $\varphi_{\text {lag }}$ is introduced by a dimensionless method, and it is defined as

$$
\varphi_{\mathrm{lag}}=\frac{t_{\mathrm{lag}}}{\tau_{\mathrm{h}}} \times 2 \pi
$$

Obviously, the phase lag can be used to evaluate to what extent the cooled surface lags behind the heated surface compared with the period of heat flux when the substrate of the MHSMIJ experiences a heat transfer process. It can be regarded as a parameter for depicting the relative response speed for a transient heat transfer.

Fig. 9 shows the results of the time lag and phase lag between the cooled surface and the heated surface under different periods of heat flux: $q=500+300 \times \sin \left(\frac{2 \pi}{\tau_{\mathrm{h}}} t\right) \mathrm{W} / \mathrm{cm}^{2}$, with the jet inlet velocity being fixed at $2.74 \mathrm{~m} / \mathrm{s}$ and $N_{\mathrm{s}}=26$. From Fig. 9, we can see that the time lag between the cooled surface and the heated surface of the heat sink substrate increases with increasing period. The time lag will reach about $10 \mathrm{~s}$ with $\tau_{\mathrm{h}}=35 \mathrm{~s}$. However, the phase lag first decreases significantly and then slightly increases with increasing period of heat flux. Obviously, for a low period of heat flux, the time lag is small but the phase lag is big; for a high period of heat flux, the time lag is big but the phase lag is small. Thereby, we can find that, the cooled surface relative response speed is comparatively slow for a low period of heat flux, and quick for high period of heat flux.

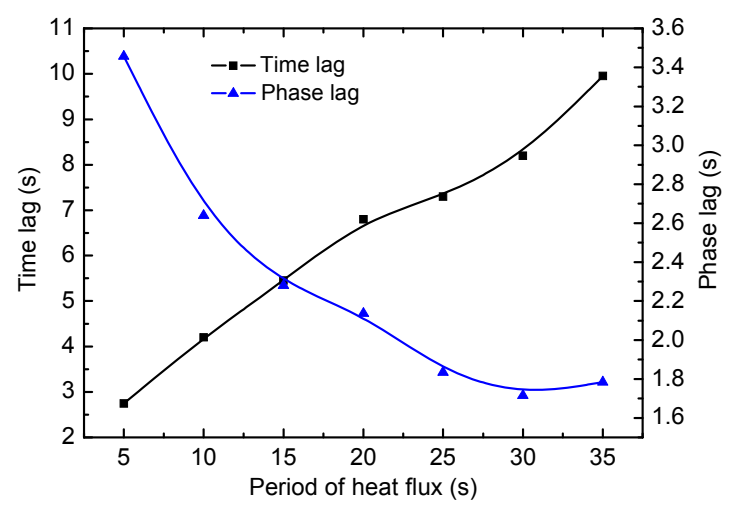

Fig. 9 Effect of period of heat flux $\tau_{\mathrm{h}}$ on the time lag and phase lag 
The effects of the amplitude of heat flux imposed upon the heated surface on the MHSMIJ performance are presented in Figs. 10-13 $\left(N_{\mathrm{s}}=26\right)$, where the heat flux on the heated surface is defined as: $q=500+A_{\mathrm{h}} \times \sin \left(\frac{2 \pi}{10} t\right) \mathrm{W} / \mathrm{cm}^{2}$, and the jet inlet velocity is fixed at $2.74 \mathrm{~m} / \mathrm{s}$. Figs. $10-13$ show the numerical simulation results of the 27th and 28th periods. It can be seen that, when the heat flux oscillates with time, the calculated values of $T_{\mathrm{S}}$ of the cooled surface are found to oscillate accordingly.

Further, the results shown in Fig. 10 are observed to oscillate in all the cases for different values of $A_{\mathrm{h}}$ with a small phase change with the sinusoidal oscillation. The time lags of all the cases are the same, at $4.2 \mathrm{~s}$. Therefore, the time lag shows little dependence on the amplitude of heat flux. We also found that the maximum temperature difference of each period increases with increasing amplitude $A_{\mathrm{h}}$. Further, Fig. 10 shows the influence of the amplitude of heat flux on the area-average temperature $T_{\mathrm{S}}$, minimum temperature $T_{\mathrm{MIN}}$, and maximum temperature $T_{\mathrm{MAX}}$ of the cooled surface. As we can see from Fig. 10, the temperature curves fluctuate periodically with time, and their fluctuations increase with increasing $A_{\mathrm{h}}$. By comparison, when the value of $A_{\mathrm{h}}$ reaches 500, the fluctuation values of $T_{\mathrm{MAX}}$, $T_{\mathrm{S}}$, and $T_{\mathrm{MIN}}$ are about $3.8 \mathrm{~K}, 3 \mathrm{~K}$, and $2.5 \mathrm{~K}$, respectively.

However, when looking into the fluctuations of $T_{\mathrm{S}}$ and $T_{\mathrm{MAX}}$ of the heated surface shown in Fig. 11, we found that the fluctuation of $T_{\mathrm{MAX}}$ is much higher than those of the cooled surface shown in Fig. 10. Here, the fluctuation amplitudes of $T_{\mathrm{MAX}}$ and $T_{\mathrm{S}}$ on the heated surface are over $11 \mathrm{~K}$ and $10 \mathrm{~K}$, respectively. Comparing these results with those in Fig. 10, the attenuations of the fluctuations in $T_{\mathrm{MAX}}$ and $T_{\mathrm{S}}$ are over $6 \mathrm{~K}$ and $7 \mathrm{~K}$, respectively. However, a lower amplitude of heat flux imposed upon the heated surface will not cause such higher fluctuations, and the attenuation will also become small. For example, the fluctuation of $T_{\mathrm{MAX}}$ on the heated surface for $A_{\mathrm{h}}=100$ is about $1.5 \mathrm{~K}$, which causes the whole system to fluctuate at a very low level; the attenuation of the fluctuation is also very slight. Therefore, when taking into account the longevity of the heat sink, a smaller amplitude of heat flux is more favorable.

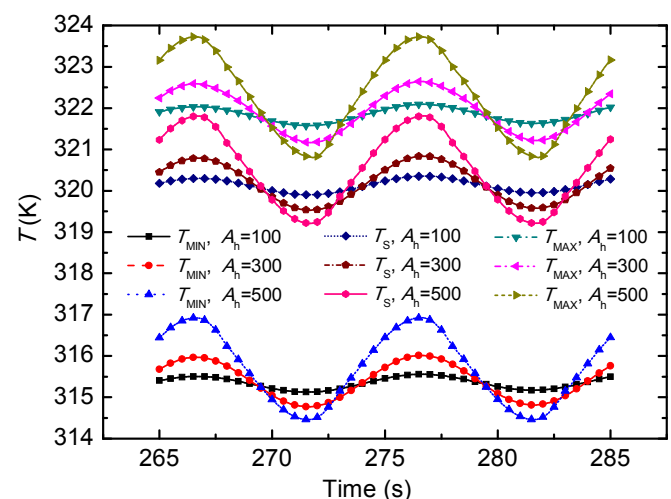

Fig. 10 Effect of the amplitude of heat flux on $T_{\mathrm{MIN}}, T_{\mathrm{S}}$, and $T_{\mathrm{MAX}}$ at the cooled surface

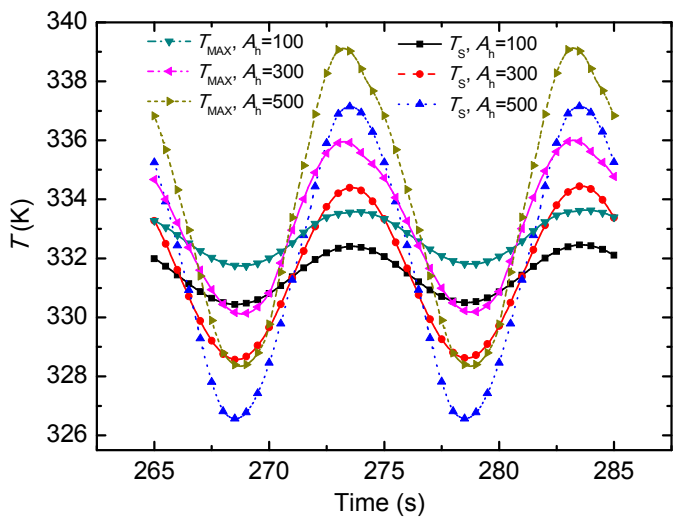

Fig. 11 Effect of the amplitude of heat flux on $T_{\mathrm{S}}$ and $T_{\text {MAX }}$ at the heated surface

From Fig. 12, $T_{\mathrm{S}, \mathrm{P}, \mathrm{H}}$ and $T_{\mathrm{S}, \mathrm{P}, \mathrm{C}}$ also fluctuate very slightly with increasing amplitude of heat flux. For all cases the values of $T_{\mathrm{S}, \mathrm{P}, \mathrm{H}}$ and $T_{\mathrm{S}, \mathrm{P}, \mathrm{C}}$ are around $331.8 \mathrm{~K}$ and $320.2 \mathrm{~K}$. Without doubt, $\Delta T_{\mathrm{m}, \mathrm{P}, \mathrm{H}}$ increases much more significantly than $\Delta T_{\mathrm{m}, \mathrm{P}, \mathrm{C}}$, with increasing amplitude of the heat flux. When the amplitude of the heat flux changes from 100 to 500 , the value of $\Delta T_{\mathrm{m}, \mathrm{P}, \mathrm{H}}$ fluctuates between $2.0 \mathrm{~K}$ and $10.6 \mathrm{~K}$, while $\Delta T_{\mathrm{m}, \mathrm{P}, \mathrm{C}}$ only increases by $2 \mathrm{~K}$. Thus, when taking the thermal stress into account under transient conditions, a significant fluctuation upon the heated surface is harmful to life span in the long term. A smaller amplitude of heat flux is better.

Fig. 13 shows the effect of amplitude on the value of $h_{\mathrm{S}}$ at the cooled surface. All the cases reach their maximum and minimum values at the same time, so do the values of $T_{\mathrm{S}}$ shown in Fig. 11. From Figs. 11 and 13, we easily find that when the value of $h_{\mathrm{S}}$ reaches its peak, the value of $T_{\mathrm{S}}$ at the cooled surface is relatively low. From Fig. 13, we can find 
another interesting phenomenon: a greater amplitude of heat flux results in a greater fluctuation of heat transfer coefficient between the fluid and the cooled surface; a greater amplitude of heat flux results in a lower average heat transfer coefficient. Obviously, the average heat transfer coefficient for $A_{\mathrm{h}}=100$ is about $73.725 \mathrm{~W} /\left(\mathrm{m}^{2} \cdot \mathrm{K}\right)$, while this value is about $73.50 \mathrm{~W} /\left(\mathrm{m}^{2} \cdot \mathrm{K}\right)$ for $A_{\mathrm{h}}=500$. The reason is that the transient periodic heat flux on the heated surface will lessen the heat transfer between the coolant and the cooled surface. However, the effect of the amplitude of the heat flux on the thermal performance of MHSMIJ is negligible as the differences among the three curves with different amplitudes are too small.

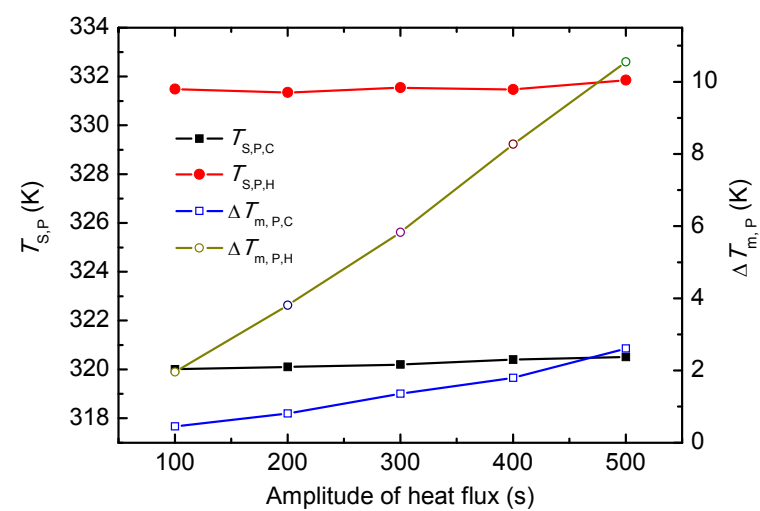

Fig. 12 Values of $T_{\mathrm{S}, \mathrm{P}}$ and maximum temperature variation at the cooled surface and the heated surface with the variation of amplitude of the heat flux

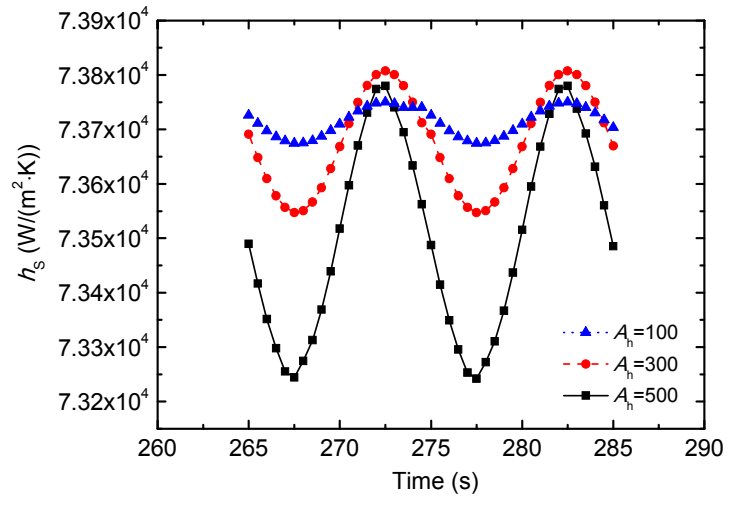

Fig. 13 Effect of amplitude of heat flux on $h_{\mathrm{S}}$ at the cooled surface

\subsection{Effect of substrate material}

Different substrate materials will also influence the heat transfer performance of MHSMIJ. To ex- plore this effect, numerical simulations have been conducted with $q=500+300 \times \sin \left(\frac{2 \pi}{10} t\right) \mathrm{W} / \mathrm{cm}^{2}$ and the jet inlet velocity being fixed at $2.74 \mathrm{~m} / \mathrm{s}$. All the working conditions of the three cases are the same, except for the material of the heat sink substrate. The three materials are $\mathrm{Cu}, \mathrm{Si}$, and AlN.

As we can see from Fig. 14, the area-weighted average temperature of the heated surface has a periodic variation with the flow time. After a few periods of oscillation, the flow and heat transfer process becomes periodically steady. So does the area-weighted average temperature of the heated surface. Generally speaking, the materials of the substrate have a significant effect on the amplitudes of $T_{\mathrm{S}}$ of the heated surface. The higher the thermal conductivity of the substrate material is, the lower the amplitude of $T_{\mathrm{S}}$ will be. Table 1 shows the amplitudes of $T_{\mathrm{S}}$ under different substrate materials when they become steady after $N_{\mathrm{s}}$ periods. The periodic variation amplitudes of the MHSMIJ with substrate materials being $\mathrm{Cu}$, AlN, and $\mathrm{Si}$ are $2.98 \mathrm{~K}, 8.235 \mathrm{~K}$, and $8.87 \mathrm{~K}$, respectively. Further, the periodic variation amplitude has a positive relationship with the heat storage coefficient. The heat storage coefficient means that under periodic heat flux conditions, the heated surface is sensitive to the thermal effect of the periodic heat flux. Its value has positive correlation with the product of density, heat capacity, and the thermal conductivity of the material. The area-weighted average temperature of the heated surface decreases with the increasing heat storage coefficient. As the heat storage coefficients of $\mathrm{Cu}, \mathrm{AlN}$, and $\mathrm{Si}$ decrease, the area-weighted average temperatures of their heated surface increase. Therefore, the material $\mathrm{Cu}$ has a smaller periodic temperature variation, which contributes to the temperature uniformity of the heated surface during one period.

By comparing $T_{\mathrm{S}, \mathrm{P}}$ with the heated surface under different materials, we found the minimum $T_{\mathrm{S}, \mathrm{P}}$ by using $\mathrm{Cu}$ substrate, and the value is $329.80 \mathrm{~K}$. However, $T_{\mathrm{S}, \mathrm{P}}$ of $\mathrm{Si}$ is the maximum, at $365.60 \mathrm{~K}$. Since lower $T_{\mathrm{S}, \mathrm{P}}$ represents a higher heat transfer performance of the MHSMIJ under the same working conditions, it means that the total cooling process is improved by using $\mathrm{Cu}$ but degraded by using $\mathrm{Si}$. 


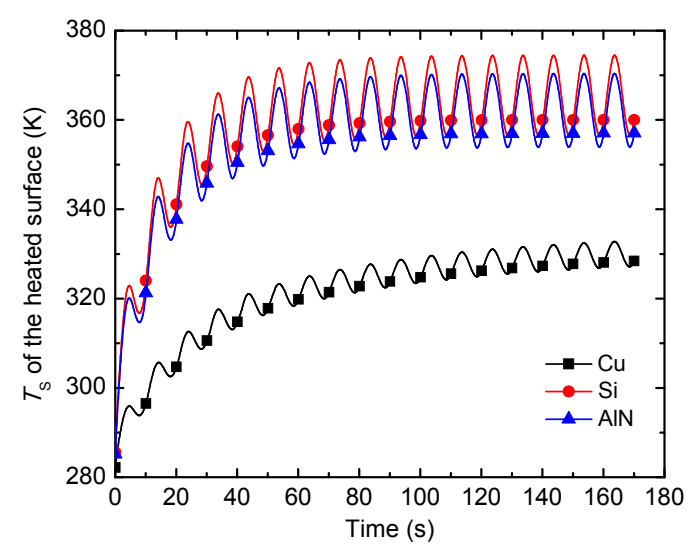

Fig. 14 Effect of substrate material on $T_{\mathrm{S}}$ of the heated surface

From Fig. 15 and Table 1, we can also see that the values of periodic variation amplitude are different under different substrate materials. We found that the time lag for $\mathrm{Cu}$ is the maximum, at about $4.2 \mathrm{~s}$, even though the thermal diffusivity of $\mathrm{Cu}$ is the largest of all the three materials.

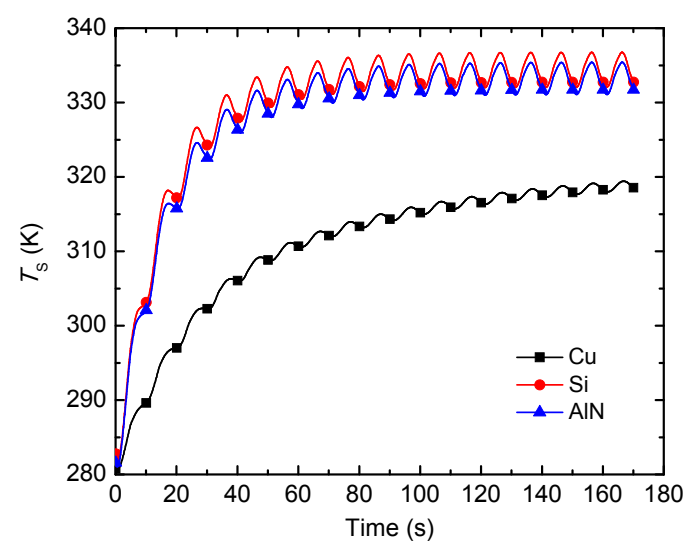

Fig. 15 Effect of substrate material on $T_{\mathrm{S}}$ of the cooled surface
Generally speaking, time lag will vary monotonically with thermal diffusivity, or rather, it should decrease with increasing thermal diffusivity. For a transient heat transfer problem, higher thermal diffusivity of the substrates will cause the whole system to transfer energy more quickly, becoming uniform in temperature distribution; as a result, the time lag should be smaller. However, the results shown in Table 2 conflict with this point. To find the detailed relationship of the time lag with the density, heat capacity, and thermal conductivity of the material, we considered a 2D transient heat conduction model (the thickness being $1 \mathrm{~cm}$, length $5 \mathrm{~cm}$, and heat transfer perpendicular to the thickness direction), used one single variable with other parameters being constant to investigate and verify the effect of these parameters on the time lag, and introduced a simple model to analyze under the same working conditions (heat flux upon the heated surface: $q=500+$ $\left.300 \times \sin \left(\frac{2 \pi}{10} t\right) \mathrm{W} / \mathrm{cm}^{2}\right)$, with $\mathrm{Cu}$ being selected as the basic material (material density $\rho_{\mathrm{s}}=8978 \mathrm{~kg} / \mathrm{m}^{3}$, $C_{\mathrm{P}}=381 \mathrm{~J} /(\mathrm{kg} \cdot \mathrm{K}), \quad k=387.6 \mathrm{~W} /(\mathrm{m} \cdot \mathrm{K})$, and thermal diffusivity $a=1.133 \times 10^{-4} \mathrm{~m} / \mathrm{s}^{2}$ ). Three cases were conducted to explore the variations of time lag by changing the magnitudes of the density, specific capacity, and thermal conductivity of the materials, and the results can be seen in Table 2 .

Table 1 Periodic variation amplitude and time lag under different materials

\begin{tabular}{cccc}
\hline Material & $\begin{array}{c}\text { Thermal diffu- } \\
\text { sivity }\left(\mathrm{m}^{2} / \mathrm{s}\right)\end{array}$ & $\begin{array}{c}\text { Periodic variation } \\
\text { amplitude }(\mathrm{K})\end{array}$ & $\begin{array}{c}\text { Time } \\
\text { lag }(\mathrm{s})\end{array}$ \\
\hline $\mathrm{Cu}$ & $1.13 \times 10^{-4}$ & 2.98 & 4.2 \\
$\mathrm{Si}$ & $9.052 \times 10^{-5}$ & 8.87 & 3.8 \\
$\mathrm{AlN}$ & $6.632 \times 10^{-5}$ & 8.235 & 3.85 \\
\hline
\end{tabular}

Table 2 Effects of material properties on the time lag

\begin{tabular}{|c|c|c|c|c|c|c|c|c|}
\hline \multicolumn{3}{|c|}{ Case 1: effect of density } & \multicolumn{3}{|c|}{ Case 2: effect of specific capacity } & \multicolumn{3}{|c|}{ Case 3: effect of thermal conductivity } \\
\hline $\begin{array}{c}\rho_{\mathrm{s}} \\
\left(\mathrm{kg} / \mathrm{m}^{3}\right)\end{array}$ & $\begin{array}{c}a \\
\left(\times 10^{-4} \mathrm{~m} / \mathrm{s}^{2}\right)\end{array}$ & $t_{\text {lag }}(\mathrm{s})$ & $\begin{array}{c}C_{\mathrm{P}} \\
(\mathrm{J} /(\mathrm{kg} \cdot \mathrm{K}))\end{array}$ & $\begin{array}{c}a \\
\left(\times 10^{-4} \mathrm{~m} / \mathrm{s}^{2}\right)\end{array}$ & $t_{\operatorname{lag}}(\mathrm{s})$ & $\begin{array}{c}k \\
(\mathrm{~W} /(\mathrm{m} \cdot \mathrm{K}))\end{array}$ & $\begin{array}{c}a \\
\left(\times 10^{-4} \mathrm{~m} / \mathrm{s}^{2}\right)\end{array}$ & $t_{\operatorname{lag}}(\mathrm{s})$ \\
\hline 8978 & 1.133 & 0.8 & 381 & 1.133 & 0.8 & 387.6 & 1.133 & 0.8 \\
\hline 7000 & 1.453 & 0.7 & 500 & 0.863 & 1.1 & 300 & 0.877 & 1.0 \\
\hline 5000 & 2.035 & 0.5 & 700 & 0.617 & 1.4 & 200 & 0.585 & 1.2 \\
\hline 3000 & 3.391 & 0.3 & 1000 & 0.432 & 1.7 & 100 & 0.292 & 1.7 \\
\hline 1000 & 10.17 & 0.1 & 2000 & 0.216 & 2.5 & 50 & 0.146 & 2.4 \\
\hline
\end{tabular}


From Table 2, we find that the time lag decreases with decreasing density of the material and heat capacity, and decreases with increasing thermal conductivity. However, according to the thermal diffusivity $\left(a=k /\left(\rho C_{\mathrm{P}}\right)\right)$ shown in Table 2 , we can find that the time lag decreases with increasing thermal diffusivity, which is in accordance with the aforementioned theory. Comparing the results of Tables 1 and 2 , we find that the time lag is influenced not only by thermal diffusivity, but also by some other parameters.

\subsection{Effect of periodic jet velocity}

Increasing the jet velocity is a very important method of increasing the total heat transfer rate of the MHSMIJ, so it is very significant to analyze the influence of periodic jet velocity on the thermal performance of the MHSMIJ.

To investigate the effect of amplitude of periodic jet velocity, a nomenclature, defined as the periodic average value of the area-averaged heat transfer coefficient, is shown in Eq. (16).

To analyze the effect of periodic jet velocity on the heat transfer performance of the MHSMIJ, we performed a numerical simulation with $V=10.96+$ $A_{v} \times \sin \left(\frac{2 \pi}{\tau_{v}} t\right) \mathrm{m} / \mathrm{s}$ and $q=500 \mathrm{~W} / \mathrm{cm}^{2} . A_{v}$ varies from 0 to 10 , and the period $\tau_{v}$ varies from 1 to $3 \mathrm{~s}$. The results are shown in Figs. 16 and $17\left(N_{\mathrm{s}}=26\right)$.

The values of $h_{\mathrm{S}}$ shown in Fig. 16 are observed to oscillate in all the cases for different amplitudes with a sinusoidal oscillation. When the value of $A_{v}$ is smaller $\left(A_{v}=1, A_{v}=3\right)$, the curve fluctuates more smoothly. However, when amplitudes reach higher values $\left(A_{v}=7, A_{v}=8.5\right)$, the curve fluctuates less smoothly because of violent oscillation. In addition, similar to the results as shown in Figs. 11 and 13, all the cases reach their peak values at the meantime, which also means the time lag has little dependence on the amplitude of jet velocity.

Furthermore, the effect of velocity amplitude on the heat transfer coefficient is very significant. When $A_{v}=7$, the fluctuation of $h_{\mathrm{S}}$ on the cooled surface is about $\pm 40 \%$. The higher the amplitude of velocity is, the higher the fluctuation of $h_{\mathrm{S}}$ will be. From the point of view of heat transfer, the effect of velocity amplitude is much more than that of the heat flux amplitude compared with Fig. 13, as the heat transfer process depends on the temperature gradient which largely depends on the velocity gradient. The velocity boundary layer near the wall of the channel will significantly become thinner and thicker periodically with increasing velocity amplitude, and thus, the temperature gradient will significantly and periodically increase and decrease with the jet velocity. However, increasing the amplitude of the heat flux being imposed upon the heated surface has much less influence on the velocity and temperature gradients near the wall of the channel; the only effect of increasing the amplitude of heat flux is that the cooled surface temperature will vary with time periodically; this will cause the water properties to vary with time and then cause the heat transfer coefficient to vary to a small extent as shown in Fig. 13.

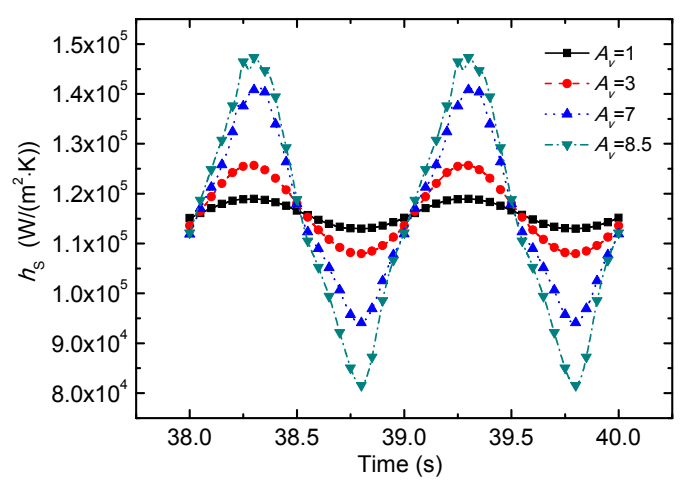

Fig. 16 Effect of amplitude of jet velocity on $h_{\mathrm{S}}$ of the cooled surface

However, the amplitudes of both the heat flux and the jet velocity will cause significant temperature variations within the substrate of MHSMIJ, which will cause frequent fluctuations of thermal stress in this region. We suggest that, under such conditions of remarkable fluctuations of transient heat flux and jet velocity, the effect of frequent thermal stress caused by transient temperature difference on the life span of MHSMIJs should be seriously considered.

Fig. 17 indicates that the amplitude of the periodic jet velocity has a significant influence on $h_{\mathrm{S}, \mathrm{P}}$, where the point $S$ shown in the figure means the value of steady jet velocity with amplitude 0 . Obviously, we find that there is a line of demarcation of heat transfer coefficient with increasing amplitude of jet velocity. The first increases smoothly with $A_{v}<7 \mathrm{~m} / \mathrm{s}$, but decreases sharply with $A_{v}>7 \mathrm{~m} / \mathrm{s}$. When the 
amplitude $A_{v}$ is around $7 \mathrm{~m} / \mathrm{s}$, the value of $h_{\mathrm{S}, \mathrm{P}}$ is largest, which means the heat transfer performance of the MHSMIJ is enhanced under such working conditions. When amplitudes range from 1 to $8 \mathrm{~m} / \mathrm{s}$, the heat transfer coefficient is higher than that of steady-state values (when $A_{v}=0$ ). From Fig. 17, we can see that a comparatively lower amplitude of the jet velocity is beneficial to the enhancement of heat transfer of the MHSMIJ, which is due to the periodic reduction and thickening of velocity and thermal boundary layers by the periodic jet velocity, where the effect of reduction by the periodic jet velocity overwhelms the effect of thickening. However, if the velocity amplitude is large enough, say, larger than $8 \mathrm{~m} / \mathrm{s}$, the velocity is sometimes less than $1 \mathrm{~m} / \mathrm{s}$, the fluid flow will significantly decrease and the velocity and thermal boundary layers become very much thicker, causing a very weak heat transfer process. Thereby, the overall heat transfer performance of the MHSMIJ is degraded by increasing the amplitude of the velocity.

Fig. 17 also shows an interesting phenomenon that the period of the jet velocity has less influence on the heat transfer performance of the MHSMIJ. The three curves with different periods have negligible quantitative differences except for the point $A_{v}=10$. Considering the jet velocity definition: $\quad V=10.96+A_{v} \times \sin \left(\frac{2 \pi}{\tau_{v}} t\right) \mathrm{m} / \mathrm{s}$, we found that the differences caused by the period of the jet velocity only occur in a very small range of the velocity amplitude. Therefore, we can draw the conclusion that the period of the jet velocity has little effect on the value of $h_{\mathrm{S}, \mathrm{P}}$.

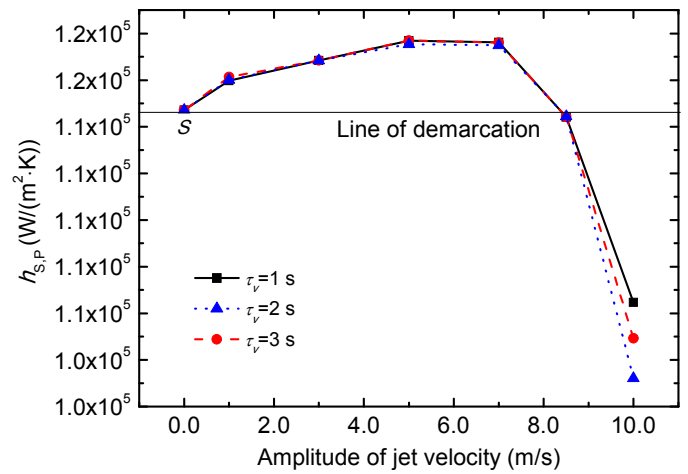

Fig. 17 Effect of period and amplitude of jet velocity on $h_{\mathrm{S}, \mathrm{P}}$ of the heated surface

\section{Conclusions}

Unsteady theoretical and experimental analysis on a 3D MHSMIJ under transient inlet and thermal boundary conditions is a very challenging and valuable work, concerning which there is little publications. We performed a numerical simulation on an MHSMIJ, theoretically explored the influence of various periodic heat fluxes and jet velocities on the fluid flow and thermal performance of it, and investigated the effects of the physical properties of different materials which cause the time lag and phase lag of transient fluctuation of temperature within the substrate. From this study, we found that:

1. The period of the periodic heat fluxes is a key parameter influencing the performance of the MHSMIJ. When periodic heat fluxes are imposed upon the heated surfaces of the MHSMIJ, the time lag will increase with increasing period, while the phase lag has an adverse trend. A longer period will not affect the overall heat transfer performance, such as $T_{\mathrm{S}, \mathrm{P}}$ and $h_{\mathrm{S}, \mathrm{P}}$, but will significantly affect the transient temperature difference and heat transfer rate, which will further affect the mechanical properties and longevity of the heat sink.

2. The amplitude of heat flux is another key parameter influencing the performance of the MHSMIJ. Increasing amplitude will not significantly affect the parameters, such as time lag, phase lag, and overall heat transfer coefficient, but will cause the system to fluctuate in temperature to a large extent, which also degrades the performance of the MHSMIJ.

3. The heat source material properties affect the time lag and phase lag. When the material of the heat sink substrate is copper, the MHSMIJ has a larger $N_{\mathrm{s}}$ and lower amplitude of temperature fluctuation. However, the time lag and phase lag are not solely affected by thermal diffusivity, some other properties perhaps have an effect on them which has not yet been discovered.

4. The amplitude of jet velocity significantly affects the transient heat transfer performance of the MHSMIJ as it greatly affects the thicknesses of the velocity and temperature boundary layers. However, the overall heat transfer performance will increase by less than $4 \%$. The period of jet velocity has negligible effect on the heat transfer performance of the MHSMIJ. 
To sum up, both the periodic heat flux imposed upon the heated surface and the periodic jet velocity will have an effect on the transient thermal behavior of the MHSMIJ but have less effect on its overall performance. However, both the periodic heat flux and the periodic jet velocity will cause non-uniform and periodic temperature distributions, which will cause thermal fatigue, and the transient thermal stresses will greatly affect the longevity of the system.

\section{References}

Açıkalın, T., Sauciuc, I., Garimella, S.V., 2005. Piezoelectric actuators for low-form-factor electronics cooling. ASME Pacific Rim Technical Conference and Exhibition on Integration and Packaging of MEMS, NEMS, and Electronic Systems collocated with the ASME Heat Transfer Summer Conference, American Society of Mechanical Engineers, USA, p.439-443.

Afroz, F., Sharif, M., 2013. Numerical study of heat transfer from an isothermally heated flat surface due to turbulent twin oblique confined slot-jet impingement. International Journal of Thermal Sciences, 74:1-13. [doi:10.1016/j. ijthermalsci.2013.07.004]

Barrau, J., Chemisana, D., Rosell, J., et al., 2010. An experimental study of a new hybrid jet impingement/ micro-channel cooling scheme. Applied Thermal Engineering, 30(14-15):2058-2066. [doi:10.1016/j. applthermaleng.2010.05.013]

Browne, E.A., Michna, G.J., Jensen, M.K., et al., 2010. Experimental investigation of single-phase microjet array heat transfer. Journal of Heat Transfer, 132(4): 041013. [doi:10.1115/1.4000888]

Camci, C., Herr, F., 2002. Forced convection heat transfer enhancement using a self-oscillating impinging planar jet Journal of Heat Transfer, 124(4):770-782. [doi:10.1115/ 1.1471521]

Chang, F., Dhir, V., 1995. Mechanisms of heat transfer enhancement and slow decay of swirl in tubes using tangential injection. International Journal of Heat and Fluid Flow, 16(2):78-87. [doi:10.1016/0142-727X(94) 00016-6]

Gül, H., 2006. Enhancement of heat transfer in a circular tube with tangential swirl generators. Experimental Heat Transfer, 19(2):81-93. [doi:10.1080/08916150500318422]

Guo, Z., Li, Z., 2003. Size effect on single-phase channel flow and heat transfer at microscale. International Journal of Heat and Fluid Flow, 24(3):284-298. [doi:10. 1016/S0142-727X(03)00019-5]

Hayase, T., Humphrey, J., Greif, R., 1992. A consistently formulated QUICK scheme for fast and stable convergence using finite-volume iterative calculation procedures. Journal of Computational Physics, 98(1): 108-118. [doi:10.1016/0021-9991(92)90177-Z]
Hofmann, H.M., Movileanu, D.L., Kind, M., et al., 2007. Influence of a pulsation on heat transfer and flow structure in submerged impinging jets. International Journal of Heat and Mass Transfer, 50(17-18):36383648. [doi:10.1016/j.ijheatmasstransfer.2007.02.001]

Huang, W., Yan, L., 2013. Progress in research on mixing techniques for transverse injection flow fields in supersonic crossflows. Journal of Zhejiang UniversitySCIENCE A (Applied Physics \& Engineering), 14(8): 554-564. [doi:10.1631/jzus.A1300096]

Huang, Y.Q., Huang, R., Yu, X.L., et al., 2013. Simulation, experimentation, and collaborative analysis of adjacent heat exchange modules in a vehicular cooling system. Journal of Zhejiang University-SCIENCE A (Applied Physics \& Engineering), 14(6):417-426. [doi:10.1631/ jzus.A1300038]

Jang, S.P., Kim, S.J., Paik, K.W., 2003. Experimental investigation of thermal characteristics for a microchannel heat sink subject to an impinging jet, using a micro-thermal sensor array. Sensors and Actuators A: Physical, 105(2):211-224. [doi:10.1016/S0924-4247(03) 00103-1]

Jensen, M.V., Walther, J.H., 2013. Numerical analysis of jet impingement heat transfer at high jet Reynolds number and large temperature difference. Heat Transfer Engineering, 34(10):801-809. [doi:10.1080/01457632. 2012.746153]

Kandlikar, S.G., Bapat, A.V., 2007. Evaluation of jet impingement, spray and microchannel chip cooling options for high heat flux removal. Heat Transfer Engineering, 28(11):911-923. [doi:10.1080/0145763070 1421703]

Lelea, D., 2010. Effects of inlet geometry on heat transfer and fluid flow of tangential micro-heat sink. International Journal of Heat and Mass Transfer, 53(17-18):35623569. [doi:10.1016/j.ijheatmasstransfer.2010.04.018]

Lelea, D., 2012. The tangential micro-heat sink with multiple fluid inlets. International Communications in Heat and Mass Transfer, 39(2):190-195. [doi:10.1016/j. icheatmasstransfer.2011.12.005]

Lelea, D., Nishio, S., Takano, K., 2004. The experimental research on microtube heat transfer and fluid flow of distilled water. International Journal of Heat and Mass Transfer, 47(12-13):2817-2830. [doi:10.1016/j. ijheatmasstransfer.2003.11.034]

Lewis, S.R., Anumolu, L., Trujillo, M.F., 2013. Numerical simulations of droplet train and free surface jet impingement. International Journal of Heat and Fluid Flow, 44:610-623. [doi:10.1016/j.ijheatfluidflow.2013. 09.001]

Li, M., 2010. Numerical Simulation of Heat Sink with Combined Micro Channels and Jet Arrays for High Heat Flux Density. PhD Thesis, Tsinghua University, Beijing, China (in Chinese).

Li, Z.X., Du, D.X., Guo, Z.Y., 2003. Experimental study on flow characteristics of liquid in circular microtubes. 
Microscale Thermophysical Engineering, 7(3):253-265. [doi:10.1080/10893950390219083]

Lienhard, J., 1995. Liquid jet impingement. Annual Review of Heat Transfer, 6(6):199-270. [doi:10.1615/ AnnualRevHeatTransfer.v6.60]

Limaye, M., Gulati, P., Vedula, R., et al., 2013. Effect of the profile of a convergent nozzle on heat transfer distribution of a flat plate impinged by an underexpanded jet. Experimental Thermal and Fluid Science, 45:75-91. [doi:10.1016/j.expthermflusci.2012.10.009]

Lu, J., Fan, L.W., Zeng, Y., et al., 2014. Effect of the inclination angle on the transient performance of a phase change material-based heat sink under pulsed heat loads. Journal of Zhejiang University-SCIENCE A (Applied Physics \& Engineering), 15(10):789-797. [doi:10.1631/ jzus.A1400103]

Ming, T.Z., Zhao, J.Y., 2012. Large-eddy simulation of thermal fatigue in a mixing tee. International Journal of Heat and Fluid Flow, 37:93-108. [doi:10.1016/j. ijheatfluidflow.2012.06.002]

Morini, G.L., Lorenzini, M., 2009. Analysis of laminar-toturbulent transition for isothermal gas flows in microchannels. Microfluidics and Nanofluidics, 7(2): 181-190. [doi:10.1007/s10404-008-0369-2]

Petroski, J., Arik, M., Gursoy, M., 2008. Piezoelectric fans: heat transfer enhancements for electronics cooling. ASME Heat Transfer Summer Conference Collocated with the Fluids Engineering, Energy Sustainability, and the 3rd Energy Nanotechnology Conferences, American Society of Mechanical Engineers, USA, p.671-677.

Poncet, S., Nguyen, T.D., Harmand, S., et al., 2013. Turbulent impinging jet flow into an unshrouded rotor-stator system: hydrodynamics and heat transfer. International Journal of Heat and Fluid Flow, 44:719-734. [doi:10. 1016/j.ijheatfluidflow.2013.10.001]

Rands, C., Webb, B.W., Maynes, D., 2006. Characterization of transition to turbulence in microchannels. International Journal of Heat and Mass Transfer, 49(17-18): 2924-2930. [doi:10.1016/j.ijheatmasstransfer.2006.02.032]

Saeid, N.H., 2009. Effect of oscillating jet velocity on the jet impingement cooling of an isothermal surface. Engineering, 1:133-139. [doi:10.4236/eng.2009.13016]

Shalchi-Tabrizi, A., Seyf, H.R., 2012. Analysis of entropy generation and convective heat transfer of $\mathrm{Al}_{2} \mathrm{O}_{3}$ nanofluid flow in a tangential micro heat sink. International Journal of Heat and Mass Transfer, 55(1516):4366-4375. [doi:10.1016/j.ijheatmasstransfer.2012. 04.005]
Tang, G.H., Li, Z., He, Y.L., et al., 2007. Experimental study of compressibility, roughness and rarefaction influences on microchannel flow. International Journal of Heat and Mass Transfer, 50(11-12):2282-2295. [doi:10.1016/j. ijheatmasstransfer.2006.10.034]

Wolf, D., Incropera, F., Viskanta, R., 1993. Jet impingement boiling. Advances in Heat Transfer, 23:1-132. [doi:10. 1016/S0065-2717(08)70005-4]

Xu, P., Mujumdar, A.S., Poh, H.J., et al., 2010. Heat transfer under a pulsed slot turbulent impinging jet at large temperature differences. Thermal Science, 14(1):271-281. [doi:10.2298/TSCI1001271X]

Xu, P., Qiu, S., Yu, M., et al., 2012. A study on the heat and mass transfer properties of multiple pulsating impinging jets. International Communications in Heat and Mass Transfer, 39(3):378-382. [doi:10.1016/j.icheatmasstransfer. 2012.01.001]

\section{中文概要}

题 目: 基于多冲击射流的微小通道热沉的瞬态热行为

目 的: 利用数值模拟方法分析动态变化的受热面热流 密度和入口速度对多冲击射流微小通道 (MHSMIJ) 的传热性能和温度波动特征的 影响。

创新点：1. 提出 MHSMIJ 热行为数值模拟方法; 2. 分析 受热面热流密度的振幅和周期对 MHSMIJ 行为 的影响; 3. 分析冲击射流速度的振幅和周期对 MHSMIJ 动态热行为的影响; 4. 分析材料热物 性参数对 MHSMIJ 的时间滞后效应的影响。

方 法: 1. 采用周期性函数来描述冲击射流的速度入口 和受热面的热流密度的波动; 2. 利用数值模拟 方法分析周期和振幅对 MHSMIJ 的动态热行为 的影响。

结 论: 1. 受热面热流密度的波动周期对 MHSMIJ 行为 的影响十分显著, MHSMIJ 的时间滞后效应随 着波动周期的增加而增加, 其基底表面温度和 表面传热系数也随之发生变化; 2. 受热面热流 密度的波动振幅对 MHSMIJ 的温度波动产生显 著的影响; 3. 冲击射流的入口速度的振幅对 MHSMIJ 的动态传热性能产生影响。

关键词：带冲击射流的微小通道; 传热; 正弦热流密 度；正弦入口速度；相位滞后 